\title{
Revealing a steroid receptor ligand as a unique PPAR $\gamma$ agonist
}

Shengchen Lin ${ }^{1,2, *}$, Ying Han ${ }^{1,2, *}$, Yuzhe Shi ${ }^{1}$, Hui Rong ${ }^{2}$, Songyang Zheng ${ }^{2}$, Shikan Jin ${ }^{1}$ Shu-Yong Lin ${ }^{1}$, Sheng-Cai Lin', Yong Li ${ }^{1,2}$

${ }^{I}$ State Key Laboratory for Cellular Stress Biology, School of Life Sciences, Xiamen University, Fujian 361005, China, ${ }^{2}$ Department of Pharmaceutical Sciences, Center for Pharmacogenetics, University of Pittsburgh, Pittsburgh, PA 15261, USA

Peroxisome proliferator-activated receptor gamma (PPAR $\gamma)$ regulates metabolic homeostasis and is a molecular target for anti-diabetic drugs. We report here the identification of a steroid receptor ligand, RU-486, as an unexpected PPAR $\gamma$ agonist, thereby uncovering a novel signaling route for this steroid drug. Similar to rosiglitazone, RU486 modulates the expression of key PPAR $\gamma$ target genes and promotes adipocyte differentiation, but with a lower adipogenic activity. Structural and functional studies of receptor-ligand interactions reveal the molecular basis for a unique binding mode for RU-486 in the PPAR $\gamma$ ligand-binding pocket with distinctive properties and epitopes, providing the molecular mechanisms for the discrimination of RU-486 from thiazolidinediones (TZDs) drugs. Our findings together indicate that steroid compounds may represent an alternative approach for designing non-TZD PPAR $\gamma$ ligands in the treatment of insulin resistance.

Keywords: PPAR $\gamma$; nuclear receptor; diabetes; crystal structure; steroid compound

Cell Research (2012) 22:746-756. doi:10.1038/cr.2011.162; published online 11 October 2011

\section{Introduction}

Peroxisome proliferator-activated receptor gamma $(\operatorname{PPAR} \gamma)$ is a nuclear receptor that plays key roles in regulating glucose homeostasis and adipocyte differentiation $[1,2]$. The synthetic PPAR $\gamma$ ligands rosiglitazone (Avandia) and pioglitazone (Actos) are thiazolidinedione derivatives (TZDs) available currently for the treatment of type 2 diabetes. While improving insulin sensitivity and lowering plasma glucose levels, the clinical use of TZDs has been tempered by side effects such as edema, weight gain and increased incidence of heart attack $[3,4]$. These adverse side effects may limit further development and clinical application of TZD-based PPAR $\gamma$ ligands. Indeed, the TZD drug Avandia was recently banned in Europe and was also

\footnotetext{
*These two authors contributed equally to this work.

Correspondence: Yong Li ${ }^{\mathrm{a}}$, Sheng-Cai Lin ${ }^{\mathrm{b}}$

a'E-mail: yongli@xmu.edu.cn

be-mail: linsc@xmu.edu.cn

Received 7 June 2011; revised 10 August 2011; accepted 18 August 2011; published online 11 October 2011
}

restricted by FDA due to its cardiovascular risks. As such, a new drug-design strategy for the identification of novel PPAR $\gamma$ ligands is needed to yield more efficacious PPAR $\gamma$-targeted drugs with reduced adverse effects [5].

The pharmacological actions of PPAR $\gamma$ ligands are mediated through the ligand-binding domain (LBD) of PPAR $\gamma$ that recruits a variety of nuclear receptor coactivators (or co-repressors) to regulate its downstream target genes depending on the nature of ligands [6-10]. The large ligand-binding pocket seen in all three PPARs has a distinct three-arm Y-shape, allowing PPARs to bind singly branched ligands or ligands with multiple branches [11]. Aside from the size and shape, the overall hydrophobic nature of the ligand-binding pocket also plays a role in controlling the binding promiscuity of nuclear receptors to various lipid soluble ligands, which also raises challenging questions on ligand selectivity among many other nuclear receptor members [12]. Indeed, many undesired side effects of drugs targeting nuclear receptors are associated with the cross-reactivity of these ligands with other members in the nuclear receptor family. On the other hand, cross-reactivity may also offer opportunities to improve therapeutic efficacy of the ligands by providing additive or complementary 
effects through simultaneously regulating several related targets $[13,14]$.

We report here the identification of the steroid compound RU-486 as an unexpected PPAR $\gamma$ agonist and also the structural basis for its binding selectivity. RU486 (Mifepristone) is a steroid compound with many medical uses such as treatment of hypercortisolism [15, 16]. Remarkably, RU-486 also displays anti-diabetic activities by reducing blood glucose levels and improving insulin sensitivity [17-20]. However, the molecular signaling pathway of RU-486 is not clear, except for its antagonist properties for steroid receptors. In this report, we attribute the medical effects of RU-486, at least in part, to its interaction with the nuclear receptor PPAR $\gamma$, revealing a hitherto unidentified signaling route for this multifaceted drug. The structure of PPAR $\gamma$ complexed with RU-486 shows a unique binding mode of RU-486 in the PPAR $\gamma$ ligand-binding pocket, with the receptor adopting the canonical active conformation. Site-directed mutations in the PPAR $\gamma$ ligand-binding pocket reveal a strong correlation of RU-486 binding and PPAR $\gamma$ activation. Moreover, RU-486 modulates the key PPAR $\gamma$ target genes expression in adipocyte differentiation, but shows a lower adipogenic activity than TZDs. Our observations therefore indicate that modifications based on RU486 may represent an alternative approach for designing non-TZD PPAR $\gamma$ ligands for the treatment of insulin resistance.

\section{Results}

\section{Identification of RU-486 as a potent PPAR ligand}

To identify new PPAR $\gamma$ agonists, we screened chemical libraries based on the AlphaScreen biochemical assay, which is widely used for detecting liganddependent interactions between nuclear receptors and their co-activators $[21,22]$. As expected, results from Biomol FDA drug library revealed that TZD drugs pioglitazone and troglitazone acted as PPAR $\gamma$ activators, together with rosiglitzazone, which was used as a positive control (Supplementary information, Figure S1). Strikingly, the steroid compound RU-486 also substantially induced the co-activator-binding activity of PPAR $\gamma$. To further examine the characteristics of RU486 in activating nuclear receptors, Cos7 cells were cotransfected with a Gal4-driven reporter, together with plasmids encoding various nuclear receptor LBDs fused with the Gal4 DNA-binding domain. Consistent with previous observations, RU-486 showed a weak agonist activity on the glucocorticoid receptor (GR) in the absence of endogenous and exogenous glucocorticoids (Figure 1A) [23]. In agreement with the results from
AlphaScreen biochemical assay, treatment of RU-486 significantly induced the transactivation activity of $\operatorname{PPAR} \gamma$, with weak cross-reactivity for PPAR $\alpha$ and $\delta$ (Figure 1A). In contrast, treatment of RU-486 had no impact on a variety of other nuclear receptors tested,
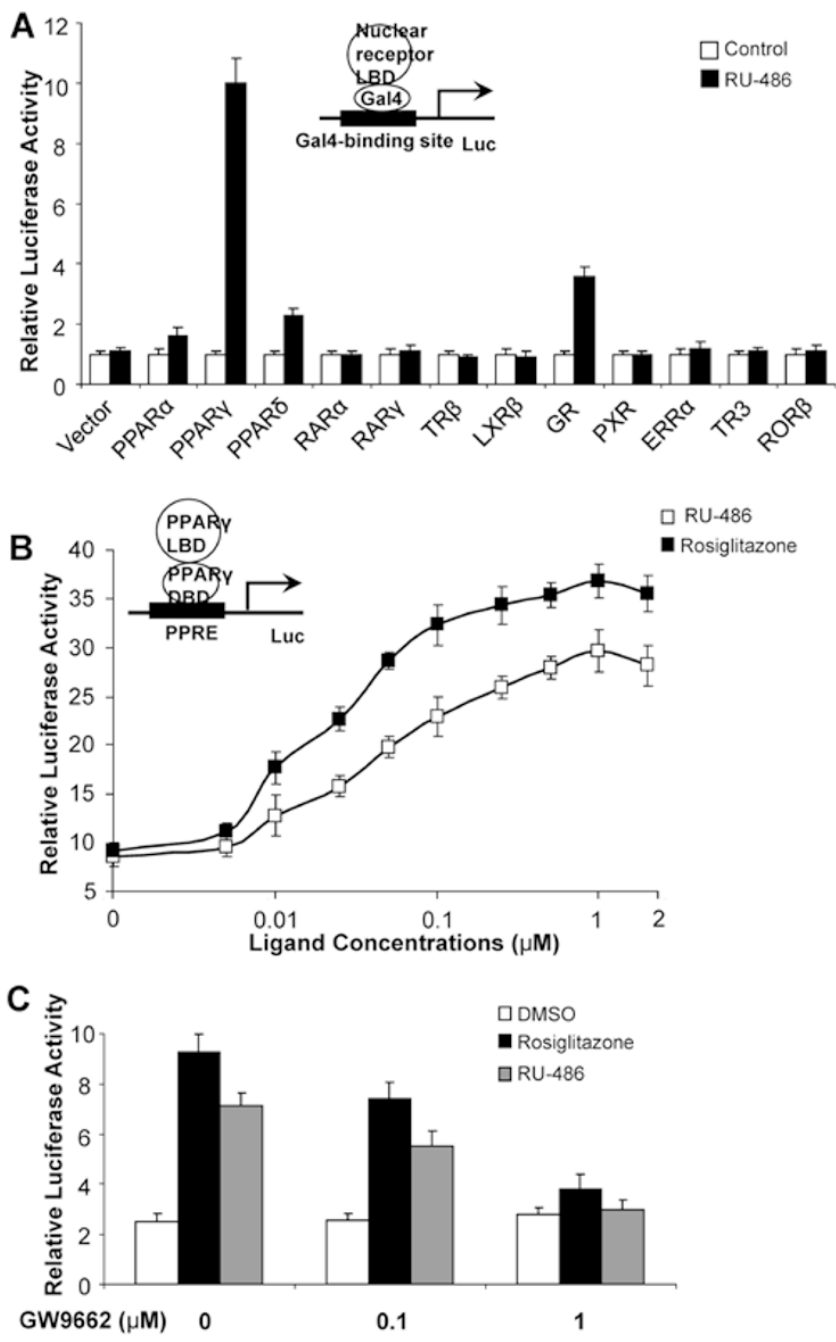

Figure 1 RU-486 is a high affinity PPAR y agonist. (A) Receptorspecific transactivation by RU-486. Cos 7 cells were cotransfected with pG5Luc reporter together with the plasmids encoding various nuclear receptors LBDs fused with the Gal4 DNA-binding domain. After transfection, cells were treated with DMSO or $1 \mu \mathrm{M}$ RU-486. (B) Dose responses of RU-486 in transactivating PPAR $\gamma$. Cos7 cells were co-transfected with plasmids encoding full-length PPAR $\gamma$ and a PPRE luciferase reporter. After transfection, cells were treated with DMSO or various concentrations of RU-486 and rosiglitazone. (C) PPAR activation by RU-486 was inhibited by PPAR $\gamma$ antagonist GW9662. Cos7 cells were co-transfected with plasmids encoding full-length PPAR $\gamma$ and a PPRE luciferase reporter. After transfection, cells were treated with RU-486, together with various concentrations of GW9662. 
including retinoic acid receptor- $\alpha$ and $-\gamma$, thyroid hormone receptor- $\beta$, liver $X$ receptor- $\beta$, or pregnane $X$ receptor (Figure 1A). Unlike the antagonistic properties of RU-486 on progesterone receptor (PR) and GR, RU486 did not show inhibitory effects on PPAR $\gamma$ activity when tested with receptor-specific agonists (Supplementary information, Figure S2). Moreover, RU-486induced PPAR $\gamma$ activity was also observed in the context of the full-length receptor and a PPAR $\gamma$ response reporter (Figure 1B). In addition, the full dose-response curve in vivo (Figure 1B) revealed that RU-486 activated PPAR $\gamma$ in a concentration-dependent manner. Further, RU-486mediated PPAR $\gamma$ activity was inhibited by the PPAR $\gamma$ specific antagonist GW9662 in cell-based reporter assays (Figure 1C) [24], all indicating that RU-486 is a bona fide PPAR $\gamma$ ligand.

To unravel the biochemical mechanism of PPAR $\gamma$ activation by RU-486, we determined the ability of RU486 in promoting recruitment of co-regulator motifs by PPAR $\gamma$, using the AlphaScreen biochemical assay. As shown in Figure 2, both RU-486 and rosiglitazone strongly enhanced the interaction of PPAR $\gamma$ with various co-activator LXXLL motifs from the family of steroid receptor co-activators (SRC1-2, SRC1-4, SRC2-3 and SRC3-3), CBP and PGC-1 $\alpha$, but not a co-repressor motif from NcoR (NcoR-2), reaffirming that RU-486 functions as an agonist through direct binding to PPAR $\gamma$.

\section{$R U-486$ regulates PPAR $\gamma$-target genes in adipocytes}

To further assess the effects of RU-486 on the

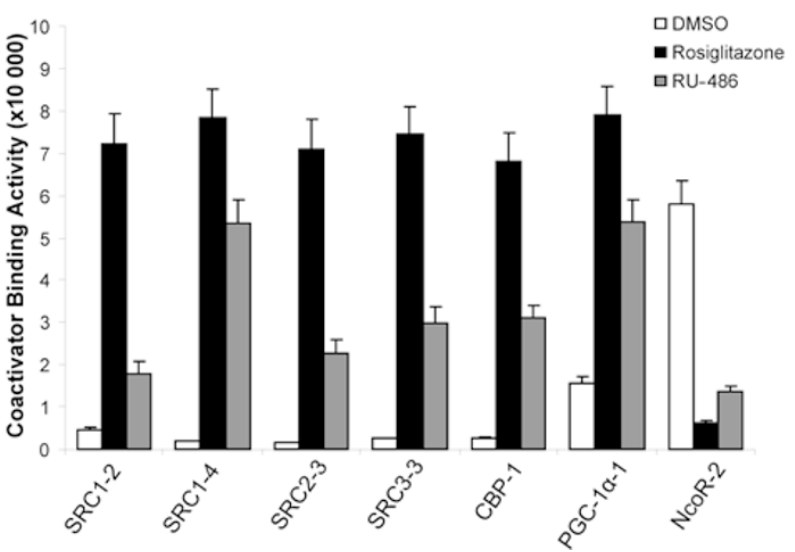

Figure 2 The transcriptional properties of PPAR $\gamma$ in response to RU-486 ligand. RU-486 promotes the interaction of co-activator LXXLL motifs with PPAR $\gamma$. Modulation of the interaction of PPAR $\gamma$ LBD with various co-activator LXXLL motifs and corepressor motifs in response to $1 \mu \mathrm{M} R U-486$ was shown by AlphaScreen assays. The peptide sequences are listed in experimental procedures.
Table 1 Data collection and refinement statistics

\begin{tabular}{|c|c|}
\hline & PPAR $\gamma / R U-486$ \\
\hline \multicolumn{2}{|l|}{ Data collection } \\
\hline Space group & C 2221 \\
\hline \multicolumn{2}{|l|}{ Cell dimensions } \\
\hline $\mathrm{a}, \mathrm{b}, \mathrm{c}(\AA)$ & $53.22,95.78,125.29$ \\
\hline$\alpha, \beta, \gamma \quad\left(^{\circ}\right)$ & $90,90,90$ \\
\hline Resolution $(\AA)$ & $50.0-2.5(2.54-2.50) *$ \\
\hline Rsym & $0.068(0.482)$ \\
\hline $\mathrm{I} / \sigma$ & $65.4(2.5)$ \\
\hline Completeness (\%) & $99.6(97.1)$ \\
\hline Redundancy & $8.6(4.7)$ \\
\hline \multicolumn{2}{|l|}{ Refinement } \\
\hline Resolution $(\AA)$ & $31.4-2.5$ \\
\hline No. reflections & 11435 \\
\hline Rwork / Rfree & $19.6 / 27.7$ \\
\hline \multicolumn{2}{|l|}{ No. atoms } \\
\hline Protein & 2207 \\
\hline Ligand/ion & 32 \\
\hline Water & 5 \\
\hline \multicolumn{2}{|l|}{ B-factors } \\
\hline Protein & 67.8 \\
\hline Ligand/ion & 67.1 \\
\hline Water & 53.3 \\
\hline \multicolumn{2}{|l|}{ R.m.s. deviations } \\
\hline Bond lengths $(\AA)$ & 0.009 \\
\hline Bond angles $\left({ }^{\circ}\right)$ & 1.4 \\
\hline
\end{tabular}

*Values in parentheses are for highest-resolution shell. r.m.s.d is the root mean square deviation from ideal geometry of protein

${ }^{\mathrm{a}} \mathrm{R}_{\mathrm{sym}}=\sum|\mathrm{I} a v g-\mathrm{I} i| / \sum \mathrm{I} i$

${ }^{b} R_{\text {factor }}=\sum\left|F_{\mathrm{P}}-\mathrm{F}_{\text {Pcalc }}\right| / \sum \mathrm{F}_{\mathrm{p}}$, where $\mathrm{F}_{\mathrm{p}}$ and $\mathrm{F}_{\text {pcalc }}$ are observed and calculated structure factors, $\mathrm{R}_{\text {free }}$ was calculated from a randomly chosen $8 \%$ of reflections excluded from refinement and $\mathrm{R}_{\text {factor }}$ was calculated for the remaining $92 \%$ of reflections.

physiological function of PPAR $\gamma$, we studied PPAR $\gamma$ activated adipogenesis in 3T3-L1 preadipocyte cells. Compared with rosiglitazone, RU-486 induced weaker adipocyte differentiation, as indicated by oil red $\mathrm{O}$ staining (Figure 3A). We further performed PPAR $\gamma$-target gene analysis of 3T3-L1 cells treated with RU-486. Similar to rosiglitazone, RU-486 also autoregulated the expression of the PPAR 2 gene [25] (Figure 3B). As shown in Figure $3 \mathrm{~B}$, the expression of differentiationdependent PPAR $\gamma$-target genes, such as $a P 2$ [26], $L P L$ [27], CD36 [28] and adiponectin [29], was also induced by RU-486, but to a lower extent than rosiglitazone. As such, the gene expression profile analysis is consistent with the results of oil red O staining. Further, RU-486- 


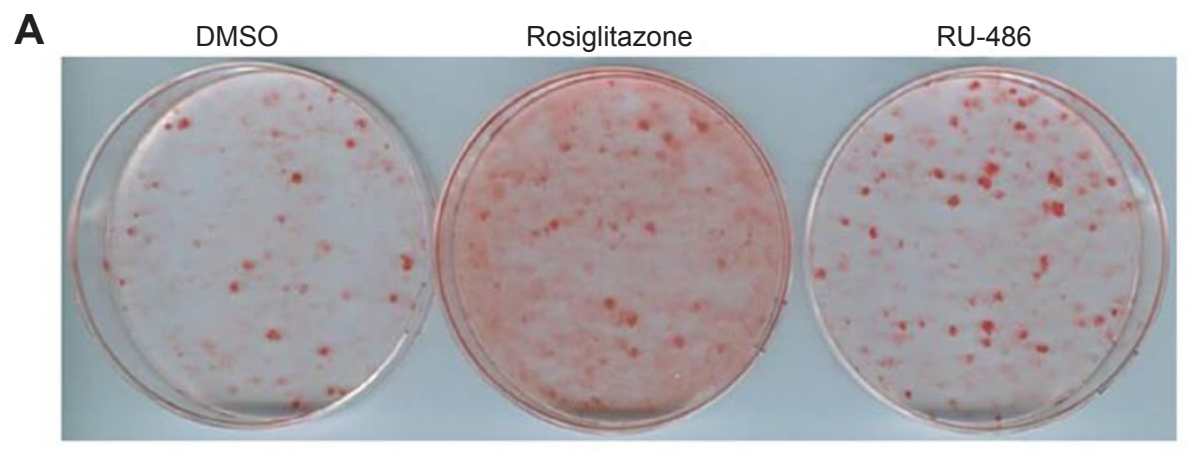

B
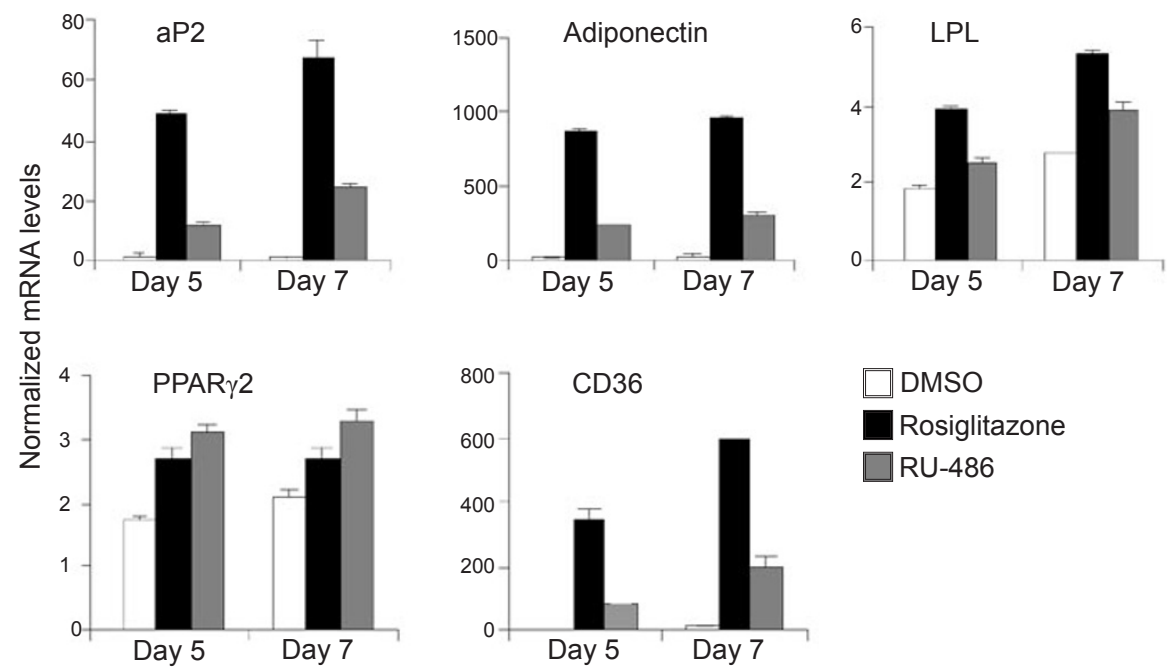

Figure $3 \mathrm{RU}-486$ regulates PPAR $\gamma$-target genes in adipogenesis and adipocytes. (A) Oil red O staining of 3T3-L1 cells after treatment with $1 \mu \mathrm{M}$ ligands indicated for 7 days. (B) Gene expression profile during the adipocyte differentiation of 3T3-L1 cells induced by $1 \mu \mathrm{M}$ ligands indicated.

mediated PPAR $\gamma$-target gene regulation was reduced by the PPAR $\gamma$-specific antagonist GW9662, reaffirming that RU-486 affects gene expression at least in part by directly activating PPAR $\gamma$ (Supplementary information, Figure S3). Overall, these results indicate that RU-486 is a potent activator of PPAR $\gamma$-responsive genes during adipocyte differentiation but with a lesser effect on adipogenesis, suggesting a potential advantage over TZD drugs.

Structural analysis of the PPARy LBD in complex with $R U-486$

To determine the molecular basis for the high binding affinity of RU-486 by PPAR $\gamma$, we solved the crystal structure of PPAR $\gamma$ complexed with RU-486, and the SRC1-2 LXXLL motif at $2.5 \AA$ resolution. The data statistics and the refined structures are summarized in Table 1 . The structure reveals that the RU-486-bound PPAR $\gamma$
LBD adopts a canonical active conformation that resembles the rosiglitazone-bound PPAR $\gamma$ structure (Figure 4A) $[30,31]$. Specifically, the PPAR $\gamma$ LBD is composed of $13 \alpha$-helices and four short $\beta$-strands that are folded into a three-layer helical sandwich. The C-terminal AF-2 helix is positioned in the active conformation by packing tightly against the main domain of the LBD.

PPAR $\gamma /$ RU-486 and PPAR $\gamma /$ rosiglitazone displayed a similar LBD structure with both ligands docking at a similar binding site in the PPAR $\gamma$ pocket (Figure 5A and $5 \mathrm{~B}$ ). Superposition of the ligand-bound structures revealed that the steroid core of RU-486 aligned well with rosiglitazone, suggesting that the steroid core occupies a well-conserved ligand-binding site in PPAR $\gamma$ (Figure 4B). In fact, this is also the very location that accommodates various endogenous PPAR $\gamma$ ligands [32, 33]. In addition to the conserved binding mode by the steroid core, the distinct dimethylaniline side chain of 

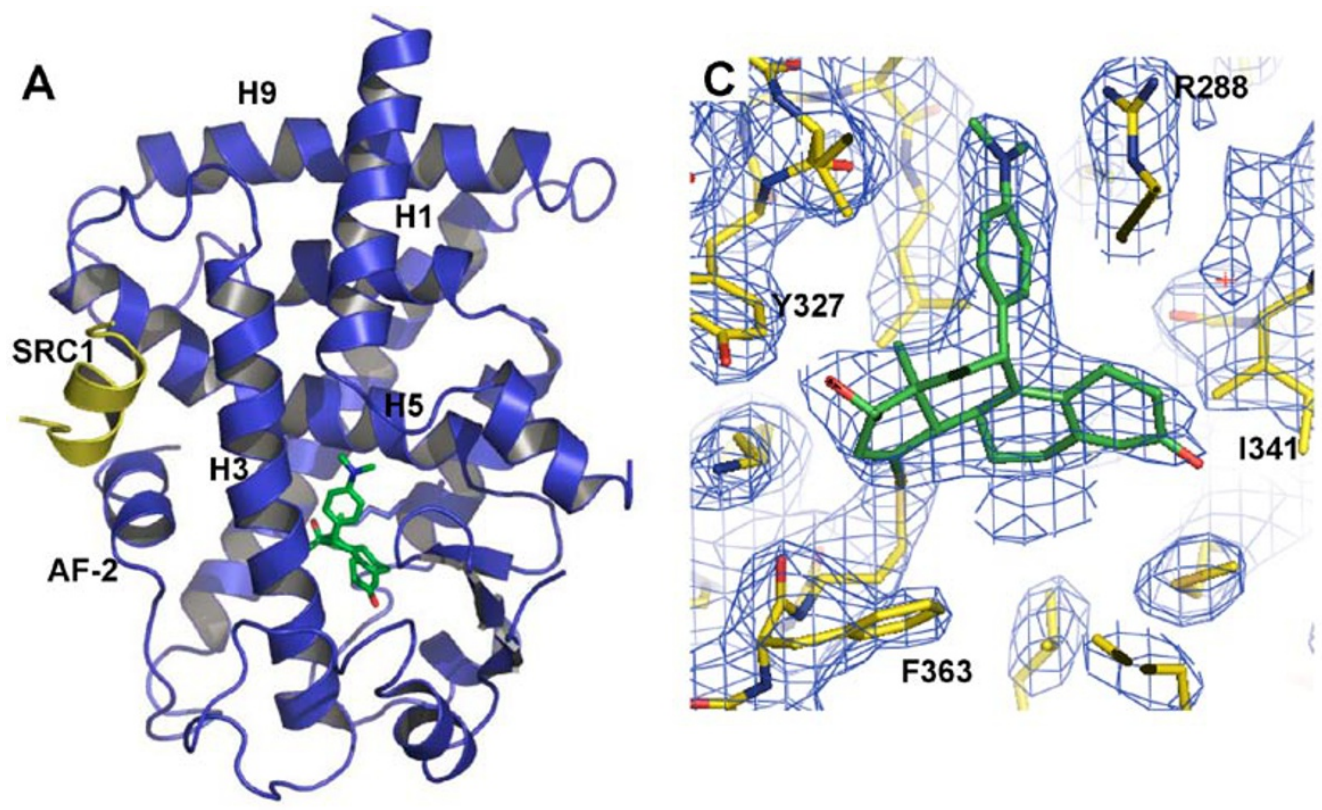

B

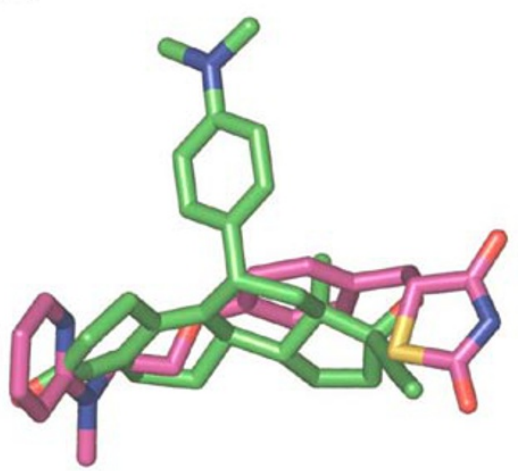

D

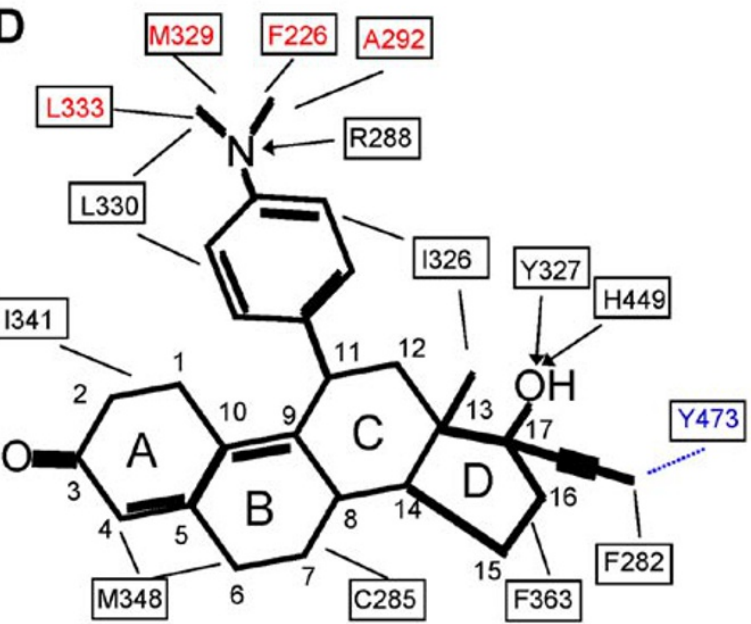

Figure 4 Recognition of RU-486 by PPAR $\gamma$. (A) The structures of RU-486 bound with PPAR $\gamma$ LBD in ribbon representation. PPAR $\gamma$ LBD is colored in blue and the SRC1 motif is in yellow. The bound RU-486 is shown in stick representation with carbon and oxygen atoms depicted in green and red, respectively. (B) Superposition of RU-486 (green) with rosiglitazone (purple). (C) 2Fo-Fc electron density map (1.0 $\sigma)$ showing bound RU-486 to the PPAR $\gamma$ LBD. The bound RU-486 is shown in stick representation with carbon and oxygen atoms depicted in green and red, respectively. (D) Schematic representation of PPAR $\gamma-R U-486$ interaction. The residues labeled red are unique contacts for RU-486 not observed for rosiglitazone, while the residue in blue indicates the one that lost contact with RU-486. Key hydrocarbon positions of RU-486 molecule are indicated. Hydrophobic interactions are indicated by lines and hydrogen bonds are indicated by arrows from proton donors to acceptors.

RU-486 was apparent from the highly revealing electron density map shown in Figure 4C. The binding of RU-486 to PPAR $\gamma$ was stabilized by a combination of hydrogen bonds and hydrophobic interactions (Figure 4D). Compared with rosiglitazone, the shorter steroid core of RU-486 resulted in fewer contacts with residues that outline the cavity (Figure 4B). However, the loss of these hydrophobic contacts was compensated by several hydrogen bonds and hydrophobic interactions created by the dimethylaniline side chain of RU-486, which were not observed in the rosiglitazone-bound PPAR $\gamma$ structure (Figure 4D).

RU-486 possesses antagonist activity for steroid receptors such as the GR. The opposing roles of RU-486 in GR and PPAR $\gamma$ can be possibly explained by the specific position of the RU-486 dimethylaniline side chain in the PPAR $\gamma$ pocket. Superposition of the RU-486/PPAR $\gamma$ structure with RU-486/GR structure revealed two distinct 

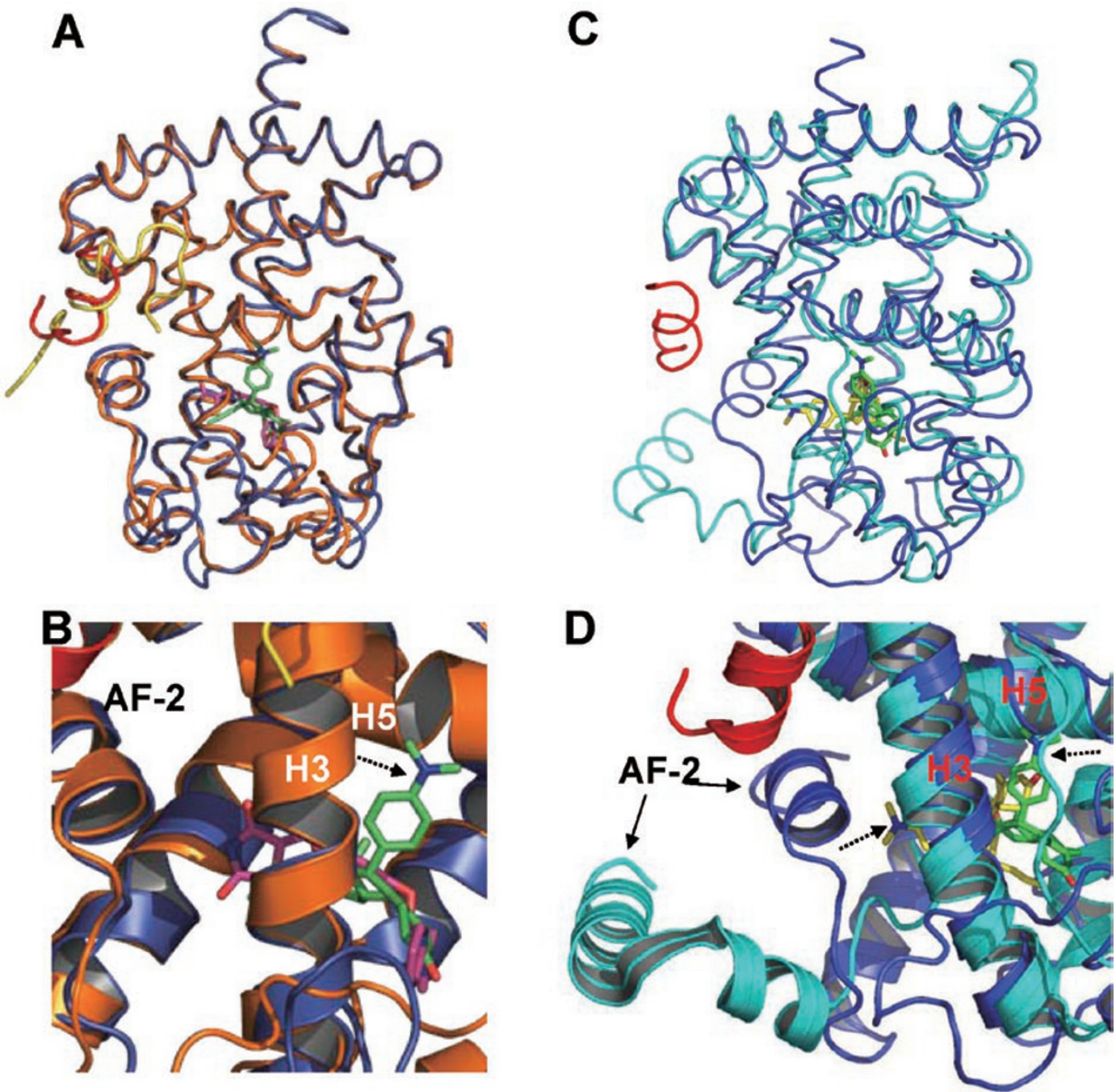

Figure 5 Superposition of the RU-486-bound PPAR $\gamma$ to rosiglitazone-bound PPAR $\gamma$ and RU-486-bound GR LBD. (A, B) Overlays of the PPAR $\gamma$-RU486 structure (blue) with the PPAR $\gamma$-rosiglitazone (gold) structure, where ligand RU-486 is in green and rosiglitazone is in purple. (C, D) Overlays of the PPAR $\gamma-R U 486$ structure (blue) with the GR-RU-486 structure (cyan), where ligand RU-486 is in green for PPAR $\gamma$ and the GR-bound RU-486 is in yellow. The dashed arrows indicate the positions of the dimethylaniline side chain of RU486.

orientations of RU-486 binding (Figure 5C and 5D). In RU-486/GR structure, the dimethylaniline side chain of RU-486 points to helix 12 (AF-2), thus interfering with the configuration of the active conformation of GR [34]. Interestingly, the binding mode of RU-486 to PR was similar to that of GR [35]. In contrast to the binding mode of RU-486 to the steroid receptors GR and PR, the dimethylaniline side chain of RU-486 adapts to the specific microenvironment in PPAR $\gamma$ composed of residues from helix 3 , helix 5 and a loop between helix 1 and helix 2 (Figures 4A and 5B). Instead of pointing to helix 12 (AF-2) as observed in steroid receptors, the dimethylaniline side chain orientates toward helix 5 of
PPAR $\gamma$ (Figures 4A, 5C and 5D). Overall, the threedimensional structure provides critical insights into the molecular basis for the function of RU-486 as a potent PPAR $\gamma$ activator and informs the design of RU-486 derivatives with improved selectivity to PPAR $\gamma$.

The unique binding mode of RU-486 in the PPARy pocket

To validate the roles of pocket residues in RU-486 binding and PPAR $\gamma$ activation, we mutated several key residues that contact different groups of RU-486 and tested the transcriptional activity of these mutated PPAR $\gamma$ in response to RU-486 in cell-based reporter assays using full-length PPAR $\gamma$ and a PPAR $\gamma$ response 

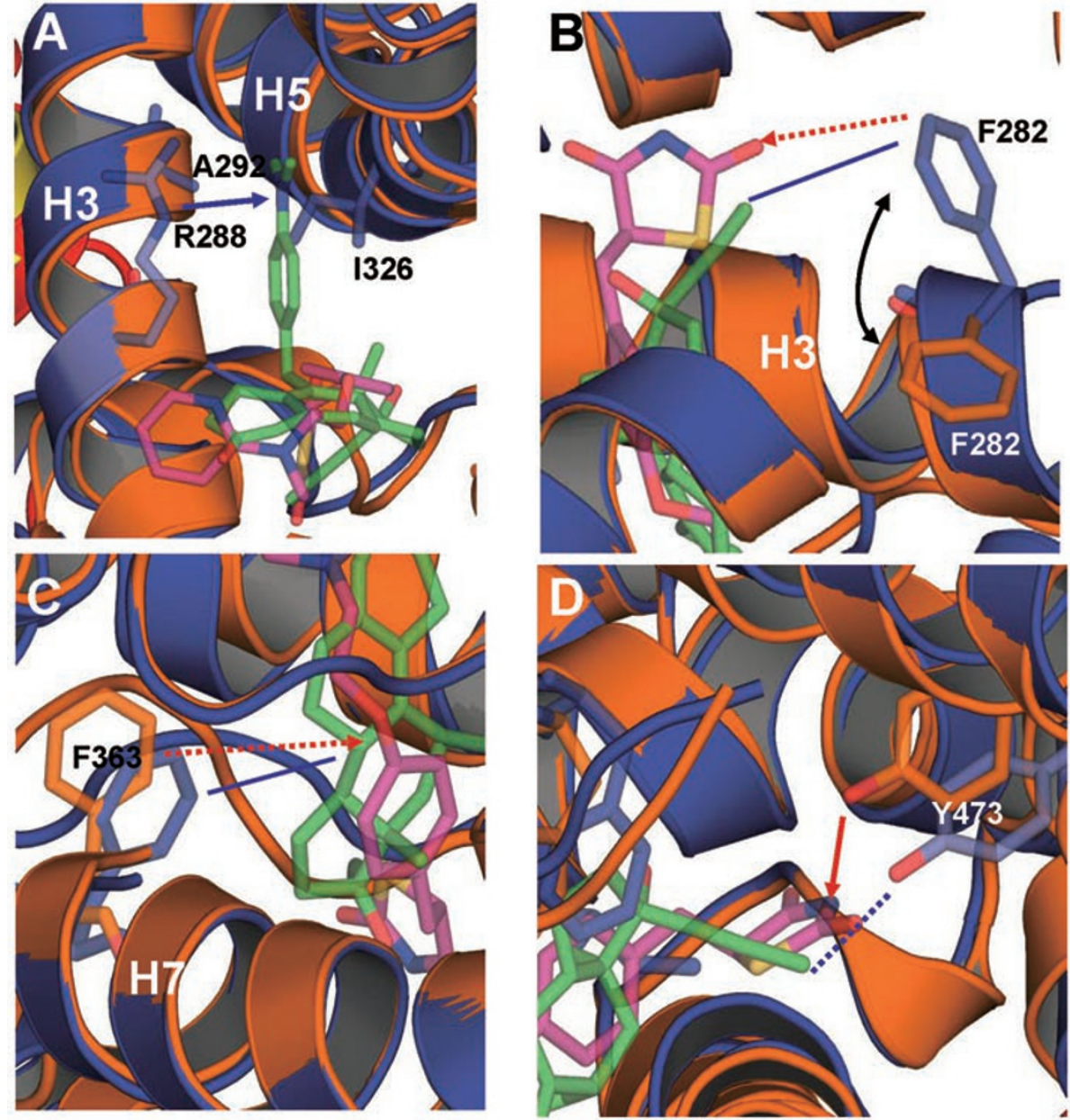

$\mathbf{E}$

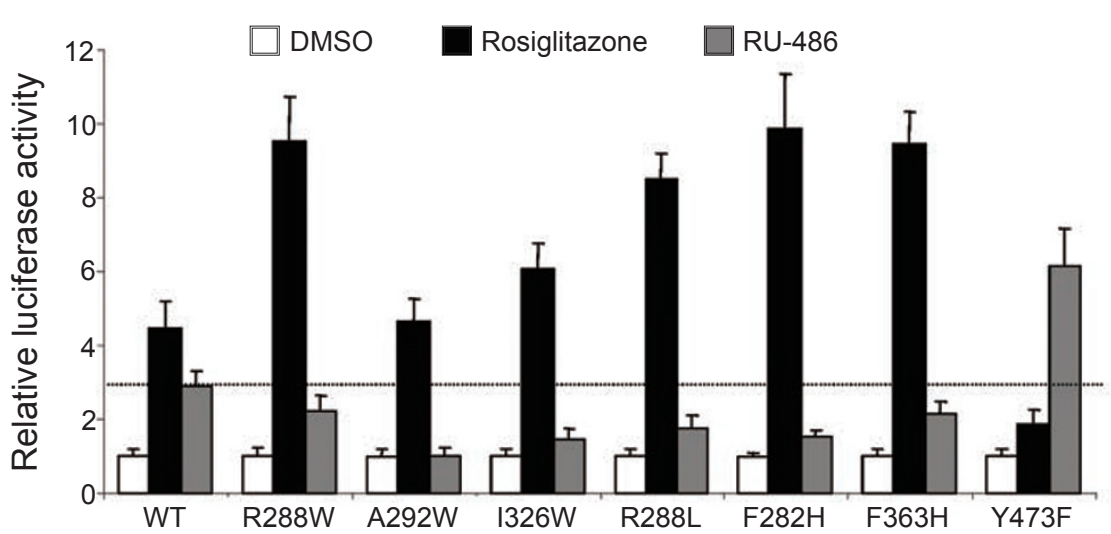

Figure 6 Functional correlation of the RU-486/ PPAR $\gamma$ interactions. (A-D) Molecular determinants of the interaction between PPAR $\gamma$ with ligand RU-486. Overlays of the PPAR $\gamma-R U-486$ structure (blue) with the PPAR $\gamma$-rosiglitazone (gold) structure, where ligand RU-486 is in green and rosiglitazone is in purple. The hydrophobic interactions and hydrogen bonds are shown with lines and arrows, respectively. The potential hydrophobic interactions and hydrogen bonds, if the corresponding mutations are made as indicated in E, are shown in dashed lines and dashed arrows, respectively. The blue lines indicate the interactions between PPAR $\gamma$ and RU-486, while the gold lines indicate the interaction between PPAR $\gamma$ and rosiglitazone. (E) Effects of mutations of key PPAR $\gamma$ residues on its transcriptional activity in response to RU-486 in cell-based reporter gene assays. Cos7 cells were co-transfected with plasmids encoding full-length PPAR $\gamma$ or PPAR $\gamma$ mutants as indicated in the figure together with a PPRE luciferase reporter. The cells were treated with $1 \mu \mathrm{M} \mathrm{RU}-486$ and rosiglitazone, respectively. The dashed line indicates the activation level of wild-type PPAR $\gamma$ by RU-486. 
reporter. R288, A292 and I326 are three PPAR $\gamma$ pocket residues that form contacts with the dimethylaniline side chain of RU-486 (Figure 6A). Three mutations were designed to reduce the size of the pocket arm in PPAR $\gamma$ that accommodates the dimethylaniline side chain by changing the corresponding residue to a tryptophan, thereby preventing the binding of the bulky RU-486 ligand. In contrast to interfering with RU-486 binding, these mutations were predicted to stabilize the rosiglitazone-bound PPAR $\gamma$ structure by filling up the empty arm not occupied by rosiglitazone with bulky tryptophan side chains. Accordingly, all three mutations abolished or substantially reduced RU-486-mediated PPAR $\gamma$ transcriptional activity, but the mutants retained the ability to be activated by rosiglitazone (Figure 6E). In addition, the nitrogen on the dimethylaniline side chain of RU486 forms a hydrogen bond with R288 (Figure 6A). Mutation of this residue to the hydrophobic leucine decreased the activation PPAR $\gamma$ by RU-486, but enhanced the activation PPAR $\gamma$ by rosiglitazone (Figure 6E). Together, these data suggest that interactions between the dimethylaniline side chain of RU-486 and PPAR $\gamma$ are required for stable binding of RU-486.

The 17 $\beta$-hydroxy group of the steroid core of RU486 forms several hydrogen bonds with the surrounding PPAR $\gamma$ residues, including Y327 from helix 5 and H449 from helix 10 (Figure 4D). These interactions were observed for both RU-486- and rosiglitazone-bound PPAR $\gamma$, thereby supporting a critical conserved mechanism for ligand-mediated activation of PPAR $\gamma$. Interestingly, the 17-(1-propynyl) group and the D ring of RU486 formed a stronger hydrophobic environment instead of a hydrophilic one for the corresponding position of rosiglitazone (Figure 6B and 6D). Accordingly, PPAR $\gamma$ displayed a great conformational flexibility to accommodate different bound ligands. Conformational changes in two surrounding pocket residues (F282 and F363) were evidenced when the RU-486/PPAR $\gamma$ complex was overlaid on the rosiglitazone/PPAR $\gamma$ structure (Figure 6B and 6C). The hydrophobic side chains of F282 and F363 shifted from their rosiglitazone-bound conformation toward the hydrophobic group of RU-486, thus stabilizing RU-486 binding by making additional hydrophobic interactions with RU-486. The mutations disrupting these interactions showed distinct results on the activation of PPAR $\gamma$ by RU-486 and rosiglitazone, highlighting the differential roles of these residues in recognizing RU-486 and rosiglitazone (Figure 6E).

Notably, while a hydrogen bond between the ligand and Y473 on helix 12 is critical in rosiglitazone-bound PPAR $\gamma$, it is not seen in the RU-486-occupied receptor structure due to the hydrophobic nature of the 17-(1- propynyl) group at this position (Figure 6D). As such, a Y473F mutation should favor the hydrophobic interaction between PPAR $\gamma$ and RU-486 (Figure 6D). Indeed, the RU-486-mediated PPAR $\gamma$ transcriptional activity was substantially increased by this mutation, while rosiglitazone-mediated activity was decreased (Figure 6E), further affirming that the PPAR $\gamma$ ligand-binding pocket has unique properties that dictate the discrimination between RU-486 and rosiglitazone.

\section{Discussion}

RU-486 (Mifepristone) was developed as a GR antagonist that also shows anti-progestin and antiandrogen activities. In this paper, we have used structural studies in combination with biochemical and gene expression analysis to provide strong evidence that the steroid compound RU-486 is also a unique PPAR $\gamma$ ligand. First, RU-486 is able to activate the transcriptional activity of PPAR $\gamma$ LBD and full-length PPAR $\gamma$ in cellbased reporter assays. In addition, RU-486-mediated PPAR $\gamma$ activity was inhibited by the PPAR $\gamma$-specific antagonist GW9662. Second, the interaction of PPAR $\gamma$ with co-activators was enhanced by the binding of this ligand. Further, the crystal structure of PPAR $\gamma$ complexed with RU-486 has revealed a clear binding mode of the RU-486 ligand in which the steroid core occupies the conserved ligand-binding pocket, and the unique side chain adopts a distinct binding mode with new epitopes on PPAR $\gamma$. The RU-486-bound PPAR $\gamma$ adopts an active conformation, further underscoring the agonist nature of this ligand. Moreover, the biological significance of RU-486 binding to PPAR $\gamma$ was further supported by the adipocyte gene expression analysis in 3T3-L1 cells. Taken together, we have provided convincing evidence that RU-486 regulates the transcriptional activity of PPAR $\gamma$ by binding to its LBD.

The specific interactions between the critical LBD residues of PPAR $\gamma$ and RU-486 provide critical perspectives regarding the recognition of RU-486 by PPAR $\gamma$. Our structural observations indicate that the PPAR $\gamma$ ligand-binding pocket has a unique shape, carrying both hydrophilic and hydrophobic properties that allow for discrimination of various ligands. Compared with the rosiglitazone/PPAR $\gamma$ structure, RU-486 initiates several new contacts with PPAR $\gamma$ through its dimethylaniline side chain to offset the loss of interactions with a few residues on PPAR $\gamma$ including one critical epitope on the AF-2 helix, which is used by both natural PPAR $\gamma$ ligands and synthetic TZDs $[32,33]$. The cavity occupied by the dimethylaniline side chain belongs to one arm of the Y-shaped pocket, which is highly conserved 
among all three PPARs. However, the epitopes on this arm cavity have not been entirely used by previously identified PPAR $\gamma$ ligands like rosiglitazone, despite that these residues are known to align around the PPAR $\gamma$ pocket. The differential binding modes of RU-486 vs the therapeutic drug TZDs may subsequently impart the differential modulation of the overall structure of PPAR $\gamma$, thereby affecting target gene regulation and physiological outcomes induced by various PPAR $\gamma$ ligands. Thus, the unique characteristics of the dimethylaniline side chain may represent a new pharmacophore that can be optimized for selectively targeting PPAR $\gamma$.

The physiological function of RU-486 has been linked to steroid hormone receptor signaling pathways. Indeed, RU-486 was initially developed as an antagonist targeting GR and has many clinical values including therapeutic potentials for hypercortisolism in Cushing's syndrome. Notably, RU-486 has also been shown to improve insulin sensitivity in rodents [20]. In fact, the glucocorticoid antagonism regulates both hepatic and adipocyte gene expression, which improves glucose control in diabetic animal models $[20,36]$. Our results indicate that at least part of the RU-486 effects are in fact through targeting the nuclear receptor PPAR $\gamma$ and PPAR $\gamma$-target genes, thus uncovering a novel signaling route for RU486. Of note, the pharmacological effects of PPAR $\gamma$ activation by various ligands are involved in both adipogenic and the anti-diabetic regulation in the adipocyte $[37,38]$. Interestingly, it has been reported that RU-486 treatment did not cause the body weight gain, which is a side effect of rosiglitazone $[17,18]$. In agreement with this beneficial role of RU-486, our adipocyte gene expression analysis indicates a weaker adipogenic activity of RU486 compared to rosiglitazone. Intriguingly, the extent of PPAR $\gamma$ activation does not correlate with insulin sensitivity. In fact, mice with heterozygous loss of the PPAR $\gamma$ gene showed improved insulin sensitivity [39]. Several PPAR $\gamma$ agonists with weaker or partial activity display greater anti-diabetic potency [40, 41]. Similarly, the distinct properties of RU-486 may provide a novel means for the activation of PPAR $\gamma$ or the treatment of PPAR $\gamma$-regulated diseases including insulin resistance.

The discovery of RU-486 as a potent PPAR $\gamma$ ligand suggests further functional links between the roles of steroid receptors and PPAR $\gamma$ signaling in adipocyte differentiation and glucose metabolism. Since RU486 interacts with both PPAR $\gamma$ and steroid receptors, the structural mechanism may provide a basis for designing RU-486-based compounds that can be used more specifically either for PPAR $\gamma$ - or GR-regulated diseases, or for a combinatorial therapy. However, the antagonistic activity of RU-486 towards PR and GR has been associated with many undesired side effects. The beneficial and side effects arising from the crossinteraction with each receptor can be optimized by designing new RU-486-based compounds with more selectivity toward PPAR $\gamma$ or steroid receptors. Apart from the drug design, further elucidation of these two disparate signaling pathways of PPAR $\gamma$ and GR by using the RU-486-based compounds should reveal specific molecular basis for their roles in glucose homeostasis.

\section{Materials and Methods}

\section{Protein preparation}

The human PPAR $\gamma$ LBD (residues 206-477) was expressed as N-terminal $6 \times$ His fusion protein from the expression vector pET24a (Novagen). BL21 (DE3) cells transformed with each expression plasmid were grown in LB broth at $25^{\circ} \mathrm{C}$ to an OD600 of $\sim 1.0$ and induced with $0.1 \mathrm{mM}$ isopropyl 1 -thio- $\beta$ D-galactopyranoside (IPTG) at $16{ }^{\circ} \mathrm{C}$. Cells were harvested and sonicated in $200 \mathrm{ml}$ extraction buffer $(20 \mathrm{mM}$ Tris $\mathrm{pH} 8.0$, $150 \mathrm{mM} \mathrm{NaCl}, 10 \%$ glycerol and $25 \mathrm{mM}$ imidazole) per 61 of cells. The lysate was centrifuged at $20000 \mathrm{rpm}$. for $30 \mathrm{~min}$, and the supernatant was loaded on a $5 \mathrm{ml} \mathrm{NiSO}$-loaded HisTrap HP column (GE Healthcare). The column was washed with extraction buffer and the protein eluted with a gradient of 25$500 \mathrm{mM}$ imidazole. The PPAR $\gamma$ LBD was further purified with a Q-Sepharose column (Amersham Biosciences). To prepare the protein-ligand complex, we added a five-fold excess of the RU-

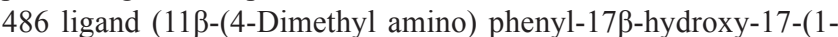
propynyl) estra-4,9-dien-3-one) to the purified protein, followed by filter concentration to $10 \mathrm{mg} / \mathrm{ml}$. The PPAR $\gamma$ LBD was complexed with two-fold of SRC1 peptide (SLTERHKILHRLLQEGSP) before filter concentration.

Crystallization, data collection and structure determination

The crystals of PPAR $\gamma / \mathrm{RU}-486$ complex were grown at room temperature in hanging drops containing $1.0 \mu \mathrm{l}$ of the above protein-peptide solutions and $1.0 \mu \mathrm{l}$ of well buffer containing $0.2 \mathrm{M}$ succinic acid, $\mathrm{pH} 7.0$, and 25\% PEG 3350. The crystals were directly flash frozen in liquid nitrogen for data collection. Diffraction data were collected with a MAR300 CCD detector at the ID line of sector-21 at the Advanced Photon Source. The observed reflections were reduced, merged and scaled with DENZO and SCALEPACK in the HKL2000 package [42]. The structures were determined by molecular replacement in the CCP4 suite (http://www.ccp4.ac.uk). Manual model building was carried out with Coot [43], followed by REFMAC refinement in the CCP4 suite.

\section{Cofactor binding assays}

The binding of the various peptide motifs to PPAR $\gamma$ LBD in response to ligands was determined by AlphaScreen assays, using a hexahistidine detection kit from Perkins-Elmer as described [22]. The experiments were conducted with approximately 20 $40 \mathrm{nM}$ receptor LBD and $20 \mathrm{nM}$ biotinylated cofactor peptides in the presence of $5 \mu \mathrm{g} / \mathrm{ml}$ donor and acceptor beads in a buffer containing $50 \mathrm{mM}$ MOPS, $50 \mathrm{mM} \mathrm{NaF}, 0.05 \mathrm{mM} \mathrm{CHAPS}$ and 0.1 
$\mathrm{mg} / \mathrm{ml}$ bovine serum albumin, all adjusted to a $\mathrm{pH}$ of 7.4.

The peptides with an N-terminal biotinylation are listed below:

SRC1-2, SPSSHSSLTERHKILHRLLQEGSP;

SRC1-4, QKPTSGPQTPQAQQKSLLQQLLTE;

SRC2-3, QEPVSPKKKENALLRYLLDKDDTKD;

SRC3-3, PDAASKHKQLSELLRGGSG

PGC-1 $\alpha-1$, AEEPSLLKKLLLAPA;

CBP-1, SGNLVPDAASKHKQLSELLRGGSG;

NCOR-2, GHSFADPASNLGLEDIIRKALMGSF.

\section{Transient transfection assay}

Cos-7 cells were maintained in DMEM containing 10\% fetal bovine serum (FBS) and were transiently transfected using Lipofectamine 2000 (Invitrogen) [22]. All mutant PPAR $\gamma$ plasmids were created using the Quick-Change site-directed mutagenesis kit (Stratagene). Before $24 \mathrm{~h}$ of transfection, 24-well plates were plated $\left(5 \times 10^{4}\right.$ cells per well). For Gal4-driven reporter assays, the cells were transfected with $200 \mathrm{ng}$ Gal4-LBDs of various nuclear receptors and $200 \mathrm{ng}$ of pG5Luc reporter (Promega). For native promoter reporter assays, the cells were co-transfected with plasmids encoding full-length nuclear receptors and their cognate luciferase reporters as follows: three human PPAR subtypes $(\alpha, \delta$ and $\gamma$ ) and PPRE-Luc. Ligands were added $5 \mathrm{~h}$ after transfection. Cells were harvested $24 \mathrm{~h}$ later for the luciferase assays. Luciferase activities were normalized to Renilla activity co-transfected as an internal control.

\section{T3-L1 differentiation and RNA analysis}

3T3-L1 preadipocytes were maintained in growth media containing 10\% FBS and differentiated as described previously [40]. Briefly, for ligand-induced adipocyte differentiation, cells were treated with $1 \mu \mathrm{M}$ rosiglitazone or RU-486 2 days after confluence. The cells were then stained with a filtered Oil Red O stock solution (0.5 g of Oil Red O (Sigma, St. Louis, MO) in 100 $\mathrm{ml}$ of isopropyl alcohol) for $15 \mathrm{~min}$ at room temperature.

Total RNA was extracted from 3T3-L1 cells with Trizol reagent (Life Technologies, Inc). RNA was reverse transcribed using the iScript cDNA Synthesis Kit (Bio-Rad). Real-time quantitative PCR analysis was performed using Power SYBR Green PCR Master Mix (Applied Biosystems). The primer sequences of all genes were reported before [5]. The mRNA expression was normalized to $36 \mathrm{~B} 4$.

\section{Accession numbers}

Coordinates and structure factors for the PPAR $\gamma /$ RU-486 complex are available in the Protein Data Bank (http://www.rcsb.org/) under ID code 3QT0.

\section{Acknowledgments}

We thank the staff at BL17U of Shanghai Synchrotron Radiation Source and sector 21 (LS-CAT) of the Advance Photo Source for assistance in data collection. Use of the Advanced Photon Source was supported by the Office of Science of the US Department of Energy. This work was supported by the National Institutes of Health Grant DK081757, and grants from the National Natural Science Foundation of China (31070646 and 30730025) and the Science Planning Program of Fujian Province (2009J1010).

\section{References}

1 Lehrke M, Lazar MA. The many faces of PPARgamma. Cell 2005; 123:993-999.

2 Wang YX. PPARs: diverse regulators in energy metabolism and metabolic diseases. Cell Res 2010; 20:124-137.

3 Yki-Jarvinen H. Thiazolidinediones. N Eng J Med 2004; 351:1106-1118.

4 Nissen SE, Wolski K. Effect of rosiglitazone on the risk of myocardial infarction and death from cardiovascular causes. N Eng J Med 2007; 356:2457-2471.

5 Waki H, Park KW, Mitro N, et al. The small molecule harmine is an antidiabetic cell-type-specific regulator of PPARgamma expression. Cell Metab 2007; 5:357-370.

6 Feige JN, Gelman L, Michalik L, Desvergne B, Wahli W. From molecular action to physiological outputs: peroxisome proliferator-activated receptors are nuclear receptors at the crossroads of key cellular functions. Prog Lipid Res 2006; 45:120-159.

7 Glass CK, Ogawa S. Combinatorial roles of nuclear receptors in inflammation and immunity. Nat Rev Immunol 2006; 6:4455.

8 Evans RM, Barish GD, Wang YX. PPARs and the complex journey to obesity. Nat Med 2004; 10:355-361.

9 Moras D, Gronemeyer H. The nuclear receptor ligand-binding domain: structure and function. Curr Opin Cell Biol 1998; 10:384-391.

10 Tsukahara T, Tsukahara R, Fujiwara Y, et al. Phospholipase D2-dependent inhibition of the nuclear hormone receptor PPARgamma by cyclic phosphatidic acid. Mol Cell 2010; 39:421-432.

11 Li Y, Lambert MH, Xu HE. Activation of nuclear receptors: a perspective from structural genomics. Structure (Camb) 2003; 11:741-746.

12 Jin L, Li Y. Structural and functional insights into nuclear receptor signaling. Adv Drug Deliv Rev 2010; 62:1218-1226.

13 Berger JP, Akiyama TE, Meinke PT. PPARs: therapeutic targets for metabolic disease. Trends Pharmacol Sci 2005; 26:244-251.

14 Michalik L, Wahli W. Guiding ligands to nuclear receptors. Cell 2007; 129:649-651.

15 Cadepond F, Ulmann A, Baulieu EE. RU486 (mifepristone): mechanisms of action and clinical uses. Annu Rev Med 1997; 48:129-156.

16 Johanssen S, Allolio B. Mifepristone (RU 486) in Cushing's syndrome. Eur J Endocrinol 2007; 157:561-569.

17 Dubuc PU, Peterson CM. Ineffectiveness of parenteral fluoxetine or RU-486 to alter long-term food intake, body weight or body composition of genetically obese mice. J Pharmacol Exp Ther 1990; 255:976-979.

18 Langley SC, York DA. Effects of antiglucocorticoid RU 486 on development of obesity in obese fa/fa Zucker rats. $\mathrm{Am} \mathrm{J}$ Physiol 1990; 259:R539-R544.

19 Gettys TW, Watson PM, Taylor IL, Collins S. RU-486 (Mifepristone) ameliorates diabetes but does not correct deficient beta-adrenergic signalling in adipocytes from mature C57BL/6J-ob/ob mice. Int J Obes Relat Metab Disord 1997; 21:865-873.

20 Taylor AI, Frizzell N, McKillop AM, Flatt PR, Gault VA. 
Effect of RU486 on hepatic and adipocyte gene expression improves diabetes control in obesity-type 2 diabetes. Horm Metab Res 2009; 41:899-904.

21 Li Y, Choi M, Cavey G, et al. Crystallographic identification and functional characterization of phospholipids as ligands for the orphan nuclear receptor steroidogenic factor-1. Mol Cell 2005; 17:491-502.

22 Li Y, Suino K, Daugherty J, Xu HE. Structural and biochemical mechanisms for the specificity of hormone binding and coactivator assembly by mineralocorticoid receptor. Mol Cell 2005; 19:367-380.

23 Laue L, Chrousos GP, Loriaux DL, et al. The antiglucocorticoid and antiprogestin steroid RU 486 suppresses the adrenocorticotropin response to ovine corticotropin releasing hormone in man. J Clin Endocrinol Metab 1988; 66:290-293.

24 Leesnitzer LM, Parks DJ, Bledsoe RK, et al. Functional consequences of cysteine modification in the ligand binding sites of peroxisome proliferator activated receptors by GW9662. Biochemistry 2002; 41:6640-6650.

25 Shao D, Lazar MA. Peroxisome proliferator activated receptor gamma, CCAAT/enhancer-binding protein alpha, and cell cycle status regulate the commitment to adipocyte differentiation. J Biol Chem 1997; 272:21473-21478.

26 Bernlohr DA, Angus CW, Lane MD, Bolanowski MA, Kelly TJ Jr. Expression of specific mRNAs during adipose differentiation: identification of an mRNA encoding a homologue of myelin P2 protein. Proc Natl Acad Sci USA 1984; 81:54685472.

27 Schoonjans K, Peinado-Onsurbe J, Lefebvre AM, et al. PPARalpha and PPARgamma activators direct a distinct tissuespecific transcriptional response via a PPRE in the lipoprotein lipase gene. EMBO J 1996; 15:5336-5348.

28 Tontonoz P, Singer S, Forman BM, et al. Terminal differentiation of human liposarcoma cells induced by ligands for peroxisome proliferator-activated receptor gamma and the retinoid X receptor. Proc Natl Acad Sci USA 1997; 94:237-241.

29 Banga A, Unal R, Tripathi P, et al. Adiponectin translation is increased by the PPARgamma agonists pioglitazone and omega-3 fatty acids. Am J Physiol Endocrinol Metab 2009; 296:E480-E489.

30 Gampe RT Jr., Montana VG, Lambert MH, et al. Asymmetry in the PPARgamma/RXRalpha crystal structure reveals the molecular basis of heterodimerization among nuclear receptors. Mol Cell 2000; 5:545-555.

31 Chandra V, Huang P, Hamuro Y, et al. Structure of the intact
PPAR-gamma-RXR-nuclear receptor complex on DNA. $\mathrm{Na}$ ture 2008 ; 456:350-356.

32 Itoh T, Fairall L, Amin K, et al. Structural basis for the activation of PPARgamma by oxidized fatty acids. Nat Struct Mol Biol 2008; 15:924-931.

33 Li Y, Zhang J, Schopfer FJ, et al. Molecular recognition of nitrated fatty acids by PPAR gamma. Nat Struct Mol Biol 2008; 15:865-867.

34 Kauppi B, Jakob C, Farnegardh M, et al. The three-dimensional structures of antagonistic and agonistic forms of the glucocorticoid receptor ligand-binding domain: RU-486 induces a transconformation that leads to active antagonism. $J$ Biol Chem 2003; 278:22748-22754.

35 Raaijmakers HC, Versteegh JE, Uitdehaag JC. The X-ray structure of RU486 bound to the progesterone receptor in a destabilized agonistic conformation. J Biol Chem 2009; 284:19572-19579.

36 Jacobson PB, von Geldern TW, Ohman L, et al. Hepatic glucocorticoid receptor antagonism is sufficient to reduce elevated hepatic glucose output and improve glucose control in animal models of type 2 diabetes. J Pharmacol Exp Ther $2005 ; \mathbf{3 1 4}: 191-200$.

37 de Souza CJ, Eckhardt M, Gagen K, et al. Effects of pioglitazone on adipose tissue remodeling within the setting of obesity and insulin resistance. Diabetes 2001; 50:1863-1871.

38 Chao L, Marcus-Samuels B, Mason MM, et al. Adipose tissue is required for the antidiabetic, but not for the hypolipidemic, effect of thiazolidinediones. J Clin Invest 2000; 106:12211228.

39 Miles PD, Barak Y, He W, Evans RM, Olefsky JM. Improved insulin-sensitivity in mice heterozygous for PPAR-gamma deficiency. J Clin Invest 2000; 105:287-292.

40 Reginato MJ, Bailey ST, Krakow SL, et al. A potent antidiabetic thiazolidinedione with unique peroxisome proliferatoractivated receptor gamma-activating properties. $\mathrm{J}$ Biol Chem 1998; 273:32679-32684.

41 Rocchi S, Picard F, Vamecq J, et al. A unique PPARgamma ligand with potent insulin-sensitizing yet weak adipogenic activity. Mol Cell 2001; 8:737-747.

42 Otwinowski Z, Minor W. Processing of X-ray diffraction data collected in oscillation mode. Methods Enzymol 1997; 276:307-326.

43 Emsley P, Cowtan K. Coot: model-building tools for molecular graphics. Acta Crystallogr D Biol Crystallogr 2004; 60:2126-2132.

(Supplementary information is linked to the online version of the paper on the Cell Research website.) 